\title{
Correction to: Use of agro-wastes for Lasiodiplodia pseudotheobromae (C1136) production with sustainable bioefficacy
}

\author{
Charles Oluwaseun Adetunji, ${ }^{1,2}$ Julius Kola Oloke ${ }^{2}$ Osarenkhoe O. Osemwegie ${ }^{3,4}$ (D) \\ Chioma Bertha Ehis-Eriakha ${ }^{5}$
}

Published online: 22 September 2021

(c) Springer Nature B.V. 2021

\section{Correction to: Environment, Development and Sustainability https://doi.org/10.1007/s10668-021-01758-6}

The original version of this article unfortunately contained mistake in first name and last name of two authors, and the correct names are Charles Oluwaseun Adetunji and Julius Kola Oloke.

The original article has been corrected.

Publisher's Note Springer Nature remains neutral with regard to jurisdictional claims in published maps and institutional affiliations.

The original article can be found online at https://doi.org/10.1007/s10668-021-01758-6.

Charles Oluwaseun Adetunji

adetunjicharles@gmail.com; charliguitar@yahoo.com

1 Microbiology, Biotechnology and Nanotechnology Laboratory, Department of Microbiology, Edo State University Uzairue, Jattu, Edo State, Nigeria

2 Department of Pure and Applied Biology, Ladoke Akintola University of Technology, P.M.B 4000, Ogbomoso, Oyo State, Nigeria

3 Department of Biological Sciences, Microbiology Unit, Landmark University, P.M.B 1001, Omu-Aran, Kwara State, Nigeria

4 Landmarkuniversity SDG Group 2 (Zero Hunger), P.M.B 1001, Omu Aran, Kwara State, Nigeria

5 Environmental and Molecular Biology Laboratory, Edo State University Uzairue, Jattu, Edo State, Nigeria 